\title{
Medicolegal
}

\section{Legal delays and expense: a new proposal}

\author{
BY OUR LEGAL CORRESPONDENT
}

Unacceptable delays and expense in litigation are causing deep concern in the legal profession, and radical changes in the legal system are generally agreed to be needed. The Lord Chancellor's department is studying the possibilities. Since much of the time spent in civil trials is concerned with contested medical evidence, doctors should have their say in any proposals for change.

The purpose of this article is to invite suggestions for reform of the legal system from doctors, and to propose a possible new system.

Most civil actions in the Queen's Bench Division are claims for damages for personal injury from road traffic accidents, industrial accidents, or, less often, medical malpractice. In most such cases written medical reports from the doctors advising each party are agreed, and the trial is conducted without any doctor going into the witness box: the judge reads the agreed medical reports and decides accordingly. When the medical reports are not agreed, however, the doctors give evidence and are cross examined. They often seem to believe that if they had been allowed to sit down with the other party's doctor for a time over a cup of coffee they might have reached a measure of agreement. Certainly they rarely emerge from cross examination with any pleasure. And from a lawyer's viewpoint it is fair to say that when two well qualified expert doctors disagree in court a judge often has extreme difficulty in deciding between them.

\section{Conflict of evidence}

Sometimes what at first sight appears to be a conflict of medical evidence can be resolved only by findings of fact-which a judge is equipped to make and doctors are not. For example, a driver has suffered brain injury in a traffic accident; he claims that he has suffered a personality change. After lengthy cross examination the doctors agree that the issue depends on the testimony of independent observers of the plaintiff's behaviour before and after the accident. If the medical witnesses had discussed their proposed evidence with each other before the trial they might have agreed that their differences of view depended on how sceptical they had been about the history given by the plaintiff. If they had so agreed they could have presented an agreed medical report, leaving it to the court to decide between two positions. In other cases there is a direct conflict of medical opinion. For example, a doctor treating a plaintiff whose leg was broken by a taxi states that it was entirely reasonable for the plaintiff to take $\mathrm{x}$ weeks to get back to work. A doctor called by the taxi driver's insurers states that a reasonable man who was not swinging the lead would have taken $\mathrm{x}$ minus six weeks. How is the judge to decide?

\section{A new procedure}

A possible new procedure would be as follows:

(1) In every case where a plaintiff claims damages for personal injuries if the parties do not agree the other side's medical reports before the action is set down for trial the case will be referred to a medical referee.

(2) The Master of the Rolls, in consultation with the medical colleges and the BMA, will keep a register of panels of doctors of the highest reputation willing to act as referees divided into lists of different specialties.

(3) When a case is to be referred to a medical referee, the papers (including the medical reports) will be referred to a medical committee which will specify the specialty or specialties of referee required to decide the matter.

(4) The court will then select from the lists a referee or referees qualified to consider the evidence.

(5) There will be a hearing before the selected medical referee or referees chaired by a Queen's Counsel to make recommendations as to the decision of the medical issues in the case. The hearing would be entirely informal. No shorthand note would be taken. Medical witnesses would give evidence and be liable to cross examination, but nothing said at the hearing would be admissible in evidence at any subsequent trial, if a trial did follow. The recommendations might be as to liability (for example, in a medical malpractice action) or as to the facts upon which an assessment of damages might be based.

(6) The parties could agree in advance that they could accept the recommendation of the referee; in that event the recommendation would be binding on both parties. In default of agreement in advance the parties would have 28 days to accept or reject the recommendation. An accepted recommendation would be communicated to the trial judge and acted on by him (that is, if it included a recommendation of liability judgment would be entered).

(7) If either party refused to accept the recommendation the action would be sent for trial, and evidence on medical matters would be called afresh in the ordinary way. But either party may inform the court of the terms of the recommendation-which in this event would not be binding on the court and the court would give to it whatever weight it felt fit. If a recommendation is communicated to the court in these circumstances the medical referee may be called to give evidence about his recommendation.

\section{More settlements}

Any such scheme is likely to encourage a much higher level of settlements in litigation. In the first place medical reports are less likely to be partisan if written in the knowledge that they will be read by leading consultants, so that there will be a greater likelihood of settlement even before the stage of the hearing before the referee. If the action reaches the point of a recommendation it is very likely to be accepted provided the referee is of high standing. Indeed, the scheme could succeed only with the support and enthusiasm of the best in the profession.

Such a scheme would require amendment to the rules of court if not legislation. Order 40 of the Rules of the Supreme Court provides for the appointment of a court expert to report on questions submitted by the court. This rule, which is very rarely used, appears to be intended for the appointment of an expert who forms an opinion on the basis of his own observations rather than one who decides upon the observations and opinions of others. 
In certain of the United States similar schemes exist in relation to medical malpractice actions (not in relation to personal injury actions generally). These schemes are under attack-probably largely because of vested interests of lawyers. In Illinois in 1975 an amendment was made to the Civil Practice Act introducing such a scheme.' The next year the Supreme Court of Illinois held the legislation unconstitutional: it was held in breach of sections 1 and 9 of article VI of the Illinois Constitution because it "vested essentially judicial functions in non-judicial personnel." "No doubt some English judges would make a similar comment. "Trial by doctor" is anathema to many.

But similar legislation in New York State has been held to be constitutional and valid. ${ }^{3}$ In 1976 the New York courts held that the provision (introduced in 1974 and later amended) did not deny the fundamental right of access to the courts. ${ }^{4}$ The New York courts have commended the legislation; it was introduced to expedite medical malpractice actions, to encourage settlements, and to reduce costs. The New York courts have made it plain that the panel of referees may not only make a recommendation on liability but may make reasoned findings on causation-for example, they may make a finding that the defendant was negligent but the negligence did not hasten or contribute to the patient's death.' An amendment to the legislation permitting the terms of a unanimous recommendation of the panel to be put in evidence at a subsequent trial has also been found to be constitutional by the New York Court of Appeals, the highest court in that state. The court held that the recommendation of the panel assists rather than supplants the trier of fact in reaching a verdict since the recommendation is not binding on the court if not accepted by the parties. The court described the statute as "a legislative response to a perceived problem of increasing malpractice rates and serves to better equip the parties to mediate a settlement."

In New York the panel consists of a judge (who is not to be the trial judge if the action goes to trial), a practising doctor, and a practising lawyer. It is difficult to see the usefulness of a practising lawyer if the chairman is a judge, and the presence of a judge on the panel will presumably reduce the throughput of other work in the court.

It was in New York that a much more general use was made of a similar scheme on an experimental basis. ${ }^{7}$ Reaction to that scheme was mixed, but it secured enthusiastic praise in some quarters. Such a scheme would be likely to have more success in Britain without the complicating factor of the jury, to which the Americans are still wedded in civil proceedings. The New York Medical Expert Testimony Project was operated in all personal injury actions in the State of New York using a panel comprising a judge, a doctor, and a lawyer. In 1954 a committee of judges, lawyers, and doctors reported, "The success of this project was attributable less to its mechanics than to the quality of the men who participated in it-particularly those doctors and judges who were engaged in its day-to-day operations. The success of the future operation of the project and any adaptations of it will likewise depend upon the men who will participate. The service of the leading doctors of the community, the support from the bar, and the wise and effective use of the medical panels by judges who are earnest in improving and expediting the administration of justice are essential. ... We commend the project for consideration by courts, bar associations, and medical societies in other communities."

\section{References}

1 Illinois Revising Statute 1975 c 110, adding sections 58.2 to 58.10 to the Civil Practice Act.

2 Wright $v$ Central de Page Hospital Association (1976) 347 NE $2 d 736$.

3 Consolidated Laws of New York, Book 29 section 148 (a).

4 Comistey $v$ Arlen (1976) 390 NYS 2d 122 affirmed at 401 NYS 2d 200.

5 Wolfe $v$ Samaritan Hospital (1982) 450 NYS 2d 143.

6 Treyball $v$ Clarke September 12, 1985, No 516, New York Court of Appeals.

Anonymous. Impartial medical testimomy, a report by a special committee of the bar of the City of New York on the Medical Expert Testimony Project. New York: Macmillan Company, 1956:1-142.

\section{Medicine and the Media}

Last week the BBC's outside broadcasting unit went to town, screening programmes three times a day for five days from two hospitals in Portsmouth. "Hospital Watch" (BBC1, 17-21 February) aimed to "get away from the romanticised fictional view so often seen" and present live and recorded material on the work of the hospitals. We asked three doctors to watch the programmes.

$\mathrm{A}^{\mathrm{L}}$ L WAS REVEALED on the first night of Hospital Watch when Frank Bough announced that he and his team of commentators, Debbie, Maggie, and Robbie, would be bringing us "edited highlights" of the week's action in Portsmouth's two major hospitals. Of course - it was just another jolly sporting contest. Mrs Lee settled down to the long marathon of winning her third baby. Two short distance events were successfully completed-the insertion of a pacemaker, and a prostatic resection with cystoscopic pictures about as muddy as those we used to see as surgical dressers. And preparations were made for operating on a strangulated hernia-"a real cliffhanger this one"-and for a hip replacement. On Tuesday we had the 100 metres dash for a cardiac arrest, as well as a long distance kidney transplant. (Bad marks to the surgeon who, in his excitement, described the donor kidney as a piece of offal).

What struck me most forcefully was how cheerful everyone was and how articulate. Apart from the patients, the doctors stole the limelight. Dr Nicola Warner, for example, one of the house surgeons, was up most of the night and looked as fresh as a daisy-not at all the image for junior staff who want shorter hours. Without exception the consultants looked kind, caring, and the sort you'd "put your life in their hands." The nurses I thought had a raw deal, being interviewed rather than followed on the job. We visited the kitchens, with staff looking strangely old fashioned in pink hats and pinnies lined up in front of gleaming machines like a factory floor, and the boiler house, where an ex-navy stoker had a nice line in cannibalising bits of old wheelchairs to make new ones (part of the job, he said). Even the presenters were human: they confessed that they might faint in the theatre, and Maggie cried when the baby was born.

But the lasting impression was of patients, with such diverse conditions as gall stones, heart block, renal failure, ulcerative colitis necessitating an ileostomy, widespread bony metastases, knowledgeable about their illness and sustained by an amazing optimism.

By Wednesday Frank had secured Mrs Allen's gall stone for her grandson and we'd got through with remarkably little pain. Then there was a setback. Sandra Collins, an engaging girl who had had her teeth and jaws reset, developed extensive swelling which needed what sounded like a tracheostomy. It turned out she had a clotting problem. "Now we are entering a more realistic phase" ended Frank, and I thought cynically it's just like a soap opera. But I have to admit that it was first class entertainment and very reassuring for potential patients; the excellence of Queen Alexandra Hospital, Cosham, and St Mary's Hospital, Portsmouth, is a serious blow to those who constantly knock the NHS.-ALEX PATON, physician, London. 